\title{
The effect of calcium on the duration of acute gastroenteritis in children: A randomized clinical trial
}

\author{
Shirin Sayyahfar ${ }^{1}$, Mahnaz Sadeghian $^{2 *}$ D, Mojgan Amrolalaei $^{3}$ \\ Received: 20 Sep 2019 \\ Published: 28 Jun 2021
}

\section{Abstract}

Background: Currently, the role of calcium in reducing the duration and severity of diarrhea and its consequences has been considered as a topic of concern. The aim of this study was to evaluate the effect of oral calcilum on the duration of acute gastroenteritis in children.

Methods: This single-blind randomized clinical trial was performed from 2014 to 2016 at Ali Asghar Children's Hospital, Tehran, Iran. Totally, 124 patients (one month to twelve years old) with acute gastroenteritis were enrolled in this study. The patients were divided equally into intervention and placebo groups and received the calcium gluconate $10 \%, 0.5 \mathrm{cc} / \mathrm{kg} / \mathrm{day}$ and distinct water, respectively. Data analysis was performed using the statistical software SPSS version 20.0 for windows (SPSS Inc., Chicago, IL) and $\mathrm{p}<0.05$ was considered significant.

Results: The mean age of the intervention and placebo groups was $26.43 \pm 3.74$ and $20.84 \pm 2.70$ months, respectively, and the difference was not significant $(\mathrm{p}=0.228)$. The duration of diarrhea in the intervention and placebo groups was $5.27 \pm 2.01$ and $6.71 \pm$ 2.44 days respectively ( $\mathrm{p}=0.001)$. In the placebo group, the plasma calcium level was less than $8 \mathrm{mg} / \mathrm{dl}$ in $1(1.6 \%), 8-10 \mathrm{mg} / \mathrm{dl}$ in 55 $(88.7 \%)$ and more than $10 \mathrm{mg} / \mathrm{dl}$ in 6 cases $(9.7 \%)$. In the intervention group, there were $7(11.3 \%), 55(88.7 \%)$ and $0(0 \%)$ cases in three groups, respectively $(\mathrm{p}=0.005)$.

Conclusion: The oral calcium gluconate might shorten the duration of acute gastroenteritis. Therefore, it could be considered as an adjunctive therapy. Whether the formulation of the oral rehydration solution (ORS) will be updated in the future with adding the calcium salts remains to be defined and needs more investigations.

Keywords: Calcium, Calcium-sensing receptor, Diarrhea, Gastroenteritis, Pediatrics

Conflicts of Interest: None declared

Funding: None

*This work has been published under CC BY-NC-SA 1.0 license.

Copyright $\odot$ Iran University of Medical Sciences

Cite this article as: Sayyahfar Sh, Sadeghian M, Amrolalaei M. The effect of calcium on the duration of acute gastroenteritis in children: A randomized clinical trial. Med J Islam Repub Iran. 2021 (28 Jun);35:83. https://doi.org/10.47176/mjiri.35.83

\section{Introduction}

Diarrhea is still a leading cause of malnutrition among under -5 year- old children (1-5). According to the reports of the World Health Organization (WHO), 9\%-34\% of the childhood mortality in developing countries is due to diarrheal diseases (1), and nearly, half of these deaths are due

Corresponding author: Dr Mahnaz Sadeghian, sadeghian.m@iums.ac.ir

1. Research Center of Pediatric Infectious Diseases, Institute of Immunology and Infectious Diseases, Iran University of Medical Sciences, Tehran, Iran

2. Department of Pediatrics, School of Medicine, Hazrat-e Ali Asghar Pediatrics Hospital, Iran University of Medical sciences, Tehran, Iran

3. Department of Pediatrics, School of Medicine, Tehran University of Medical Sciences, Tehran, Iran to dehydration (6). Therefore, the mainstay of the treatment is based on rehydration therapy.

Although the fatality rate has been noticeably decreasing since the usage of oral rehydration therapy (ORT) in children $(7,8)$, the duration and severity of diarrhea have

$\uparrow$ What is "already known" in this topic:

Intestinal calcium-sensing receptor (CaSR) is a part of the antidiarrheal receptor system and if activated, can reverse the process of both secretory and inflammatory diarrheas.

\section{$\rightarrow$ What this article adds:}

In this study, oral calcium gluconate could shorten the duration of acute noncolitis diarrhea. Calcium might be adjunctive to the standard therapy of acute gastroenteritis in the future. Whether the formulation of ORS will be changed in the future is yet to be studied. 
not been changed (3). Therefore, novel, simple, as well as inexpensive and available anti-diarrheal therapies are needed, especially in poor resource countries. In recent years, many efforts have been made to find new treatments to expedite remission of this disease. Currently, the role of calcium in reducing the duration and severity of diarrhea and its consequences has been considered as a topic of concern.

Intestinal calcium-sensing receptor (CaSR) is a part of the anti-diarrheal receptor system involved, not only in intestinal secretion, absorption and motility, but also in the gut permeability and inflammatory response. When activated, it can reverse the process of both secretory and inflammatory diarrheas (3).

The CaSR is expressed by enteric mucosal cells along the entire small and large intestine. It is also localized in the enteric nervous system, with the role of modulating the intestinal fluid secretion induced by bacterial enterotoxins as well as viral enterotoxins $(9,10)$. Indeed, CaSR activation has the advantage of antidiarrheal mechanism that is not only anti-secretory but also anti-motility and anti-inflammatory (3).

Calcium as a CaSR-based nutrient might be useful in the conditioning of the gut microenvironment and intestinal homeostasis, accordingly, effective in the prevention and treatment of enterocolitis and secretory diarrheal diseases (11).

A study by Cheng and colleagues showed that diarrhea in immunocompromised children was successfully ceased within 1-2 days, following the administration of intravenous calcium, indicating the role of calcium in ameliorating diarrhea in these patients (12).

The clinical evidence supporting the effect of calcium on the improvement of diarrhea in immunocompetent children has been very limited, and the number of papers to show the effect of calcium on the improvement of diarrhea in the pediatric population is very scarce (13). Thus, this study was designed to evaluate the role of oral calcium on the duration of acute non-colitis diarrhea in immunocompetent pediatric patients.

\section{Methods}

\section{Design and Ethics}

This clinical trial was designed as a randomized, controlled, interventional, single-blind (patient blind) trial with two intervention and placebo groups.

After receiving approval from the ethics review committee of Iran University of Medical Sciences (institutional review board (IRB) approval number: IR.IUMS.REC.1393.9211165009), the research was conducted from June 22nd, 2014 to March 19th, 2016 at Ali Asghar Children's Hospital, Tehran, Iran.

The written informed consent was obtained from the guardians before enrollment. The study was in accordance with the principles of the Declaration of Helsinki. This trial was registered on May 26th, 2014 in the Iranian Registry of Clinical Trials (IRCT), ID number IRCT2015110624900N1 (http://www.irct.ir/).

\section{Participants}

Patients aged one month to twelve years hospitalized with acute gastroenteritis were enrolled in this study in a sequential manner. Indications of hospitalization included intractable vomiting, severe dehydration and unstable vital signs.

Diarrhea was defined as a daily passage of three or more loose or liquid stools; or more frequent passages than usual for the individual (1).

According to Vesikari scale, mild, moderate, and severe diarrhea were defined as $<7,7-10$, and $>10$ episodes of diarrhea per day, respectively (14).

Based on the WHO definition, from three clinical types of diarrhea (acute watery diarrhea, acute bloody diarrhea, and persistent diarrhea) (1) the patients with watery (acute non-colitis) diarrhea were enrolled. Based on laboratory examination, acute non-colitis diarrhea was defined as an increase in the number and/or consistency of the stool lasting less than two weeks with white blood cells(WBC) count and red blood cells(RBC)count less than 5 per high power field in stool examination and negative stool culture for bacteria $(15,16)$.

Children with inflammatory diarrhea and diarrhea associated with other diseases (such as urinary tract infection (UTI), sepsis, metabolic and endocrine disorders or antibiotic consumption), and those with gastroenteritis for more than two weeks (persisitent/chronic diarrhea), and those who withdrew from further cooperation with this investigation were excluded. Other exclusion criteria were congenital GI abnormality, intestinal surgery, short bowel syndrome, allergic gastroenteritis, immunodeficiency, vasculitis, and inflammatory bowel disease. Meanwhile, if the diagnosis was changed during the study, the case was excluded in the same way.

From 178 cases enrolled, some patients were excluded during the study mainly due to non-compliance of the parents to continue to participate in an investigational study. Moreover, some cases enrolled first with a diagnosis of acute gastroenteritis eventually developed other diagnoses during hospitalization (e.g., urinary tract infection) and were excluded. Finally, 124 patients entered the study in two groups of intervention and placebo after the exclusion of 54 cases (Fig. 1).

\section{Sample size}

After a thorough review of the literature, a similar study was not found; therefore we first performed a pilot study with 60 cases, and after analyzing the results obtained, the total sample size of 124 cases was identified.

According to the conducted pilot study, the mean number of days that the patients were involved with diarrhea in the intervention and placebo groups was $5.8 \pm 4.8$ and $8.0 \pm 4.0$ respectively. Considering the confidence coefficient of 0.05 and the study strength of $80 \%$, the sample size was calculated by the formula below:

$$
n=\frac{\left(z 1-\frac{\alpha}{2}+z 1-\beta\right)^{2} *\left(s 1^{2}+s 2^{2}\right)}{(\mu 1-\mu 2)^{2}}
$$




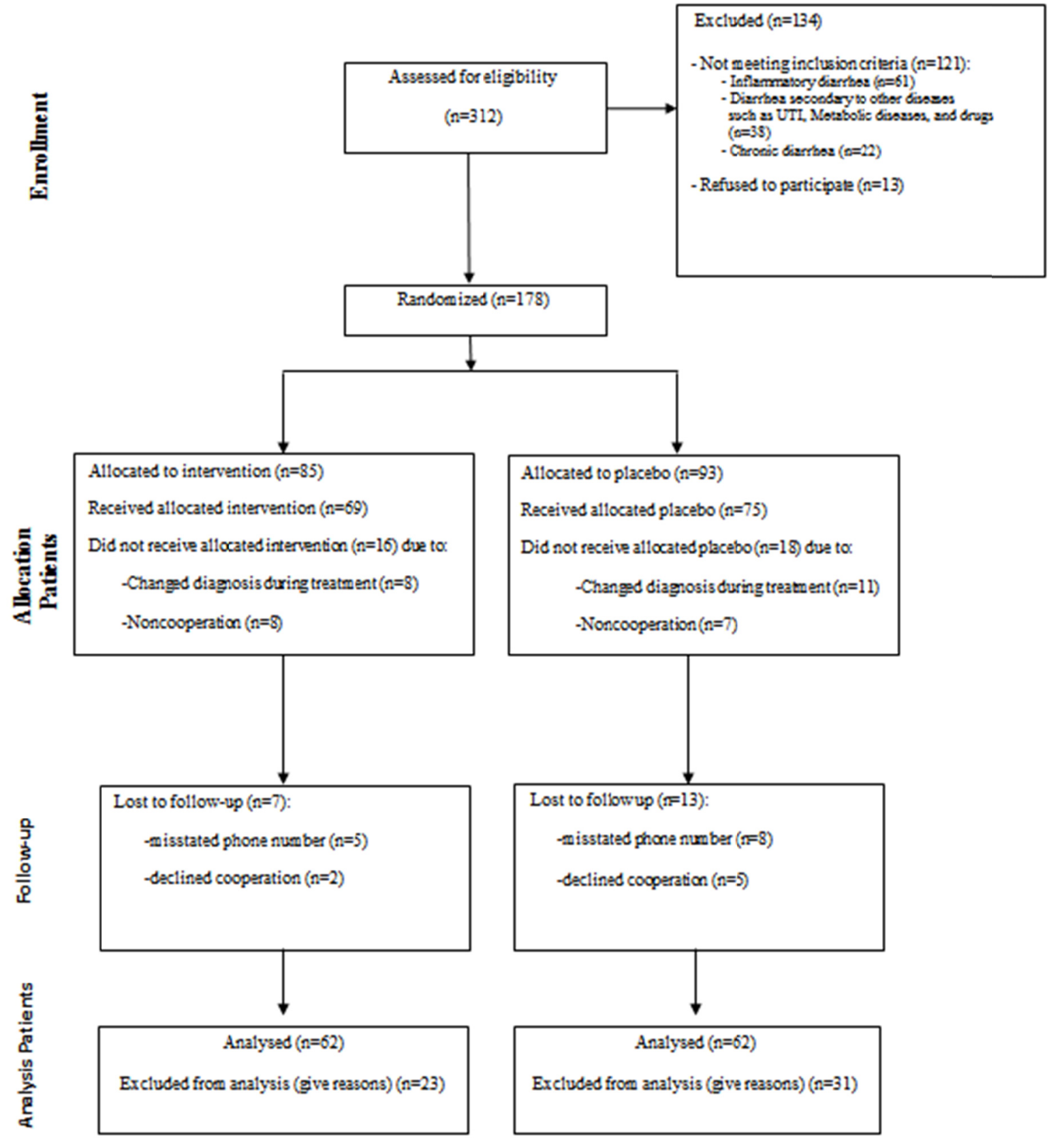

Fig. 1. Flowchart of participants

$\mu 1=5.8, \mu 2=8.0, \mathrm{~S} 1=4.8, \mathrm{~S} 2=4.0, \mathrm{Z} 1-\alpha / 2=1.96, \mathrm{Z} 1-\beta=$ 0.85

\section{Randomization, Allocation Concealment, and Blinding}

After calculating the sample size, the randomization was performed based on the random allocation rule. Subjects were randomized using the random function of the Microsoft excel software, without being subjected to stratification. One random number was selected as an intervention subject and another one was selected as a placebo subject and this circuit continued alternatively. Each selected number was dropped from the number list and never selected again.

Ultimately, 124 patients were enrolled in this study (Fig. 1 ). The calcium and distinct water were given by a similar container, and the color of the liquids was the same. The guardians (mother or caregiver) and the patients were not aware of which product was received. In the hospital, the number of episodes of diarrhea was charted by a pediatric resident, who knew the contents of the container and was aware of which one was given to the patients. She also asked the mother or guardian about the number of diarrheal episodes by phone when the patient was discharged until the end of the disease.

\section{Intervention and Procedures}

The two groups were treated with the same method for rehydration therapy and correction of the electrolyte and acid-base disorders. Both groups were treated with zinc 
sulfate $(5 \mathrm{mg}$ and $10 \mathrm{mg}$ for under and over 6 months of age, respectively) and probiotics (Kidilact 1gram, ZistTakhmir, Iran), one sachet daily as well without any antibiotics. In the intervention group, we had a singleblind trial using calcium gluconate $10 \%, 0.5 \mathrm{cc} / \mathrm{kg} /$ day orally divided into three doses for three days. The diet was similar in both groups. The electrolytes were measured in two groups of intervention and placebo 2 days after starting treatment.

\section{Outcomes}

Duration and frequency of diarrhea, and probable treatment side effects were monitored during hospital admission and after discharge. Laboratory tests such as serum sodium, potassium, calcium, bicarbonate, $\mathrm{PH}$, stool exam and culture, and also the severity of dehydration at the time of starting treatment, were measured. The electrolyte levels were followed in the two groups 2 days after starting treatment.

The primary outcome was the duration of diarrhea during hospitalization and afterward, and secondary outcomes included adverse events secondary to oral usage of calcium (e.g., nausea, vomiting, constipation, and abdominal pain).

\section{Statistical Analyses}

The qualitative variables displayed as percentiles. Qualitative variables were compared applying the Chisquare test or Fisher exact test. Quantitative variables were considered as mean and standard deviation for normal distribution. The normality of variables was checked by the Kolmogorov-Smirnov test. Comparison between quantitative variables was performed using the Independent Samples T-test and Paired Samples T-Test. Analysis of covariance (ANCOVA) and multiple linear regression analysis were used to conduct the adjustment for potential confounding variables.

Data analysis was performed using the statistical soft- ware SPSS version 20.0 for windows (SPSS

Inc., Chicago, IL) and $\mathrm{p}<0.05$ was considered significant.

\section{Results}

The flowchart of the participants has been shown in Fig. 1. The mean age of the cases in the intervention and placebo groups was $26.43 \pm 3.74$ and $20.84 \pm 2.70$ months, respectively; and the difference was not significant $(\mathrm{p}=0.228)$.

Among intervention and placebo groups, 34(60.7\%) and $41(60.3 \%)$ subjects were male, respectively, and there was not any significant difference between the two groups $(\mathrm{p}=0.96)$.

The type of diarrhea in all patients was acute non-colitis type. The duration of diarrhea for intervention and placebo groups was $5.27 \pm 2.01$ and $6.71 \pm 2.44$ days, respectively; and was significantly different $(\mathrm{p}=0.001$, Table 1$)$.

The frequency and dehydration level of diarrhea was categorized into mild, moderate, and severe, in the "intervention" and "control group "and shown in Table 1. At the baseline, there was no significant difference between the two groups regarding frequency and dehydration.

The serum level of sodium, potassium, calcium, and bicarbonate in the intervention and placebo group was shown in Table 1. The difference of the indexes, including sodium, potassium and bicarbonate between intervention and placebo groups, was not significant. In both groups, the total serum calcium level was measured before starting treatment. None of the patients had a serum calcium level of less than $8 \mathrm{mg} / \mathrm{dl}$ or more than $10 \mathrm{mg} / \mathrm{dl}$. In addition, the clinical signs and symptoms of hypocalcemia were not seen.

The serum calcium difference was statistically significant between these groups. The serum albumin and total protein were in the normal range in both groups.

In the intervention and placebo groups, 12 cases $(19.35 \%)$ and 14 cases $(22.5 \%)$ had serum bicarbonate

Table 1. Baseline comparison of serum calcium, sodium, potassium and HCO3 levels in the intervention and placebı groups

\begin{tabular}{|c|c|c|c|c|}
\hline Variables & & Intervention & Placebo & $\mathrm{p}$ \\
\hline & $<8$ & $7(11.3 \%)$ & $1(1.6 \%)$ & 0.003 \\
\hline \multirow{3}{*}{ Calcium (mg/dl) N (\%) } & $8-10$ & $55(88.7 \%)$ & $55(88.7 \%)$ & \\
\hline & $>10$ & 0 & $6(9.7 \%)$ & \\
\hline & $<130$ & $8(12.9 \%)$ & $4(6.5 \%)$ & 0.212 \\
\hline \multirow[t]{3}{*}{ Sodium (mEq/L) N (\%) } & $130-150$ & $53(85.5 \%)$ & $57(91.9 \%)$ & \\
\hline & $>150$ & $1(1.6 \%)$ & $1(1.6 \%)$ & \\
\hline & $<3.5$ & $8(12.9 \%)$ & $5(8.1 \%)$ & 0.183 \\
\hline \multirow[t]{3}{*}{ Potassium (mEq/L) N (\%) } & $3.5-5.5$ & $53(85.5 \%)$ & $57(91.9 \%)$ & \\
\hline & $>5.5$ & $1(1.6 \%)$ & 0 & \\
\hline & $<15$ & $12(19.35 \%)$ & $14(22.5 \%)$ & 0.911 \\
\hline \multirow[t]{3}{*}{$\mathrm{HCO} 3(\mathrm{mEq} / \mathrm{L}) \mathrm{N}(\%)$} & $15-20$ & $26(41.93 \%)$ & $27(43.74 \%)$ & \\
\hline & $>20$ & $24(38.7 \%)$ & $21(33.87 \%)$ & \\
\hline & Mild & $2(3.2 \%)$ & $1(1.6 \%)$ & 0.873 \\
\hline \multirow[t]{3}{*}{ Frequency of diarrhea N (\%) } & Moderate & $45(72.6 \%)$ & $40(64.5 \%)$ & \\
\hline & Severe & $15(24.2 \%)$ & $21(33.9 \%)$ & \\
\hline & Mild & $15(24.2 \%)$ & $8(12.9 \%)$ & 0.821 \\
\hline \multirow[t]{2}{*}{ Dehydration N (\%) } & Moderate & $44(71 \%)$ & $50(80.6 \%)$ & \\
\hline & Severe & $3(5.4 \%)$ & $4(6.5 \%)$ & \\
\hline Duration of diarrhea (day) & & $5.27 \pm 2.01$ & $6.71 \pm 2.44$ & 0.001 \\
\hline Calcium (mg/dl) Mean \pm SD & & $8.82 \pm 0.48$ & $8.81 \pm 1.27$ & 0.976 \\
\hline Sodium $(\mathrm{mEq} / \mathrm{L}) \mathrm{Mean} \pm \mathrm{SD}$ & & $135.98 \pm 4.78$ & $137.04 \pm 5.32$ & 0.249 \\
\hline Potassium $(\mathrm{mEq} / \mathrm{L})$ Mean \pm SD & & $3.71 \pm 0.40$ & $3.63 \pm 0.27$ & 0.215 \\
\hline
\end{tabular}


Table 2. Baseline and 2nd day of hospitalization values according the treatment in study groups

\begin{tabular}{|c|c|c|c|c|c|c|c|}
\hline \multirow[t]{2}{*}{ Variable } & \multicolumn{3}{|c|}{ Intervention } & \multicolumn{3}{|c|}{ Placebo } & \multirow{2}{*}{$\begin{array}{l}\mathrm{P} \text { value for } \\
\text { changes** }\end{array}$} \\
\hline & Baseline & After 2 days & Change & Baseline & After 2 days & Change & \\
\hline Sodium (mg/L) Mean \pm SD & $135.98 \pm 4.78$ & $137.96 \pm 2.14 *$ & $1.98 \pm 4.26$ & $137.04 \pm 5.32$ & $138.70 \pm 3.31 *$ & $1.66 \pm 3.38$ & 0.643 \\
\hline $\operatorname{Potassium}(\mathrm{mg} / \mathrm{L})$ Mean \pm SD & $3.71 \pm 0.40$ & $3.84 \pm 0.30 *$ & $1.98 \pm 4.26$ & $3.63 \pm 0.27$ & $3.72 \pm 0.19^{*}$ & $0.09 \pm 0.23$ & 0.316 \\
\hline Calcium $(\mathrm{mg} / \mathrm{L}) \quad$ Mean \pm SD & $8.82 \pm 0.48$ & $8.97 \pm 0.39 *$ & $0.15 \pm 0.26$ & $8.81 \pm 1.27$ & $8.95 \pm 0.42$ & $0.14 \pm 1.11$ & 0.928 \\
\hline
\end{tabular}

$* \mathrm{P}<0.05$ VS. baseline (obtained from Paired Samples T test)

** Obtained from Independent Samples T test.

Table 3. Multiple linear regression to assess the association between study variables and duration of diarrhea

\begin{tabular}{|c|c|c|c|c|c|c|c|c|c|}
\hline \multirow[t]{2}{*}{ Variables } & \multicolumn{3}{|c|}{ Crude model } & \multicolumn{3}{|c|}{ Adjusted model* } & \multicolumn{3}{|c|}{ Backward model } \\
\hline & $\beta$ & $95 \% \mathrm{CI}$ for $\beta$ & $\mathrm{P}$ value & $\beta$ & $95 \%$ CI for $\beta$ & $P$ value & $\beta$ & $95 \%$ CI for $\beta$ & $\mathrm{P}$ value \\
\hline Age & -0.02 & $-0.4--0.007$ & $<0.001$ & -0.02 & $-0.03--0.003$ & $<0.001$ & $-0 . .02$ & $-0.03--0.004$ & $<0.001$ \\
\hline Gender & -0.37 & $-1.2--0.52$ & 0.413 & & & & & & \\
\hline Frequency of diarrhea & -0.05 & $-0.56-0.46$ & 0.842 & & & & & & \\
\hline Dehydration & 0.04 & $-0.88-0.97$ & 0.924 & & & & & & \\
\hline Study Group** & -0.05 & $-0.56--0.46$ & 0.001 & -1.28 & $-2.11--0.46$ & 0.003 & -1.34 & $-2.17--0.51$ & 0.002 \\
\hline Sodium at baseline & -0.05 & $-0.14-0.03$ & 0.202 & & & & & & \\
\hline Potassium at baseline & -1.23 & $-2.46-0.002$ & 0.051 & -0.80 & $-1.98-0.37$ & 0.178 & & & \\
\hline Calcium at baseline & -0.21 & $-0.66-0.23$ & 0.347 & & & & & & \\
\hline
\end{tabular}

an the model.

*Study group: (1=Placebo, $2=$ Intervention)

less than 15, respectively; and the difference was not significant $(\mathrm{p}=0.9)$.

The stool white blood cells were $\leq 5 / \mathrm{HPF}$ and stool cultures were negative in both groups.

Besides vomiting, which was reported in 5 cases $(8 \%)$ after ingestion of calcium gluconate $10 \%$, and was not repeated in re-medication in 1-2 hours later, no other documented side effects were reported during the course of the disease and afterward with this dose and composition of calcium. The baseline values and values of the 2 nd day of hospitalization according to the treatment in study groups have been shown in Table 2 .

A one-way ANCOVA was used to compare the mean of serum calcium, sodium, and potassium levels in the intervention and placebo groups whilst controlling the baseline variations of these variables. Levene's test and normality checks were conducted and the assumptions met. There was a significant difference in serum potassium $[F(1,120)=6.08, p=0.01]$ levels between the intervention and placebo groups after controlling the baseline potassium level. Comparing the estimated marginal means showed that the mean of serum potassium was higher in the intervention group (mean=3.82 $\pm 0.02 \mathrm{mg} / \mathrm{L}$ ) compared to the placebo group (mean $=3.74 \pm 0.02 \mathrm{mg} / \mathrm{L})$. Moreover, there were no significant differences between the mean of serum calcium $[\mathrm{F}(1,120)=0.86, \mathrm{p}=0.35]$, and sodium $[F(1,120)=0.86, p=0.35]$ levels in the intervention and placebo groups after controlling the baseline serum variations of these variables.

In multiple linear regression analysis, there were significant associations between age $(\beta=-0.02,95 \% \mathrm{CI}$ : $-0.4-$ $0.007, \mathrm{p}<0.001)$ and study group $(\beta=-0.05,95 \% \mathrm{CI}$ : $0.56-0.46, p=0.001)$ with duration of diarrhea in the crude model. In adjusted model, after adjustment for variables with $\mathrm{p}<0.2$, there were still significant association between age $(\beta=-0.02,95 \% \mathrm{CI}:-0.03-0.003, \mathrm{p}<0.001)$ and study group $(\beta=-1.28,95 \% \mathrm{CI}:-2.11-0.46, \mathrm{p}=0.003$ ) with duration of diarrhea. In the backward linear regression model, only two variables of age $(\beta=-0.02,95 \% \mathrm{CI}$ : $0.03-0.004, p<0.001)$ and study group $(\beta=-1.28,95 \% \mathrm{CI}$ :
$-2.17-0.51, p=0.002)$ were significant and remained in the model in the final step (Table 3).

\section{Discussion}

ORS has been used for nearly 40 years and has saved millions of children's lives. Currently, we need a solution not only for rehydration therapy but also for shortening the duration and reducing the severity of diarrheal symptoms by enterotoxin-mediated excessive secretion inhibition, increased absorption, and recovery of compromised barrier function, and in a word, rapid relief of diarrheal symptoms. Since the discovery of CaSR, the time of updating the formulation of ORS to reach this target has been coming closer. It should always be taken into consideration that one death is too many, in preventable diseases such as diarrhea, and the goal is to end the child's death secondary to diarrhea by 2025(17).

As far as we are aware, this is a novel study evaluating the effect of oral calcium on reducing the duration of acute non-colitis diarrhea in an immunocompetent pediatric population. We revealed that oral calcium could decrease the duration of diarrhea for about 1.5 days in comparison to the control group. Although this reduction does not seem very significant at the first glance, it may decrease the morbidity, duration of hospitalization and prevent the post-infectious malnutrition secondary to protracted diarrhea in underdeveloped countries with poor resources.

Although there is no well-rounded study on the calcium role in the improvement of diarrhea in the immunocompetent children, some studies have revealed that using calcium in diarrhea could improve the course of the disease $(18,19)$. A study by Cheng et al. revealed a reduction of 1-3 days in the duration of diarrhea after intravenous or oral use of $1 \mathrm{meq} / \mathrm{kg}$ calcium (12). However, the cases in this study were immunocompromised, and the diarrhea was chronic. In addition, all of their cases were hypocalcemic. It must be noticed that in our study, the number of hypocalcemic patients in the intervention group was more than placebo group (7cases versus 1patient). How- 
ever, $88.5 \%$ of the patients were eucalcemic in the intervention group. Therefore, calcium usage may be efficient regardless of serum calcium status but more studies are needed to make this conclusion definitively.

Bovee-Oudenhoven et al. compared the two groups with regular calcium diet (1100mg/day) and placebo (60mg/day) when ingested live but attenuated enterotoxigenic Escherichia coli (ETEC), and showed one-day reduction in duration of diarrhea in the intervention group (20). The results of our study were close to this study. However, their cases were all adults, and healthy volunteers without any risk factors.

A study by Devrajani et al. revealed a significant difference between the serum calcium level in patients with diarrhea and control group indicating that gastroenteritis might cause hypocalcaemia (21).

Interestingly, a study by Agustina et al. showed that during a 6- month period of observation the amount of calcium diet (regular vs. low calcium milk) did not show any significant effect on the reduction of the occurrence of diarrhea in Indonesian children. Therefore, no correlation between the amount of food calcium content and prevention of diarrhea was found (13).

Since watery diarrhea results in electrolyte loss, the risk of reduced calcium may be increased. Hence, the oral consumption of calcium may reduce the risk of hypocalcaemia. In our study, the difference of serum calcium level between the intervention and placebo groups was significant. However, most of the patients were eucalcemic in both groups. So, calcium administration might be effective not only in hypocalcemic but also in eucalcemic patients.

Our study had some limitations:

1. Since we did not perform viral study due to technical and financial problems, we could not claim that the evaluated cases had exactly viral gastroenteritis. Anyhow, most cases that were included in this study in term of acute noncolitis type had clinically and epidemiologically viral diarrhea. However, it may not be very important because the aim of this study was the evaluation of calcium effect on the non-colitis- type (acute watery) diarrhea and not exactly viral diarrhea.

2. We could not compare the volume of diarrhea in the intervention and placebo patients because we could not weight the diapers in younger children.

3. The design of this study was not double blind.

4. We did not check the serum calcium level during the course of disease because the extra blood sampling was not accepted by the guardians of participants.

Although we only included acute non-colitis diarrhea, this does not mean that calcium has no effect on the course of other types of diarrhea. So, it is suggested to design a similar study with larger sample size including all types of diarrhea.

In addition, further studies with other forms of calcium salts and other concentrations of calcium are suggested so that the comparison of the results in decreasing the duration and recovery of diarrhea would possibly provide some advancement.

\section{Conclusion}

Our study revealed that oral calcium might shorten the duration of acute non-colitis diarrhea in children. Although, the result of this research is not sufficient to conclude that oral calcium gluconate is effective in reduction of the duration of acute gastroenteritis, it may be an opening research toward the advancement of the formulation of ORS.

\section{Ethical approval}

This study was approved by the ethics committee of Iran University of Medical Siciences. Informed consent was obtained from the study participants

Registration ID in Iranian Registry of Clinical Trials (IRCT): IRCT2015110624900N1

\section{Conflict of Interests}

The authors declare that they have no competing interests.

\section{References}

1. World Health Organization. Diarrheal disease.

http://www.who.int/news-room/fact-sheets/detail/diarrhoealdisease.Accessed August 30, 2018.

2. Humphries RM, Linscott AJ. Laboratory diagnosis of bacterial gastroenteritis. ClinMicrobiol Rev. 2015;28(1):3-31.

3. Cheng SX. Calcium-sensing receptor: A new target for therapy of diarrhea. World J Gastroenterol. 2016;22(9):2711-24.

4. UNICEF. UNICEF Data: monitoring the situation of children and women. https://data.unicef.org/topic/child-health/diarrhoeal-disease/. Accessed August 30, 2017.

5. Mandeville KL, Krabshuis J, Ladep NG, Mulder CJJ, Quigley EMM, Khan SA. Gastroenterology in developing countries: Issues and advances. World J Gastroenterol. 20109;15(23): 2839-54.

6. Bellemare S, Hartling L, Wiebe N, Russell K, Craig WR, McConnell D. Oral rehydration versus intravenous therapy for treating dehydration due to gastroenteritis in children: a meta-analysis of randomised controlled trials. BMC Med. 2004;2:11.

7. Munos MK, Walker CL, Black RE. The effect of oral rehydration solution and recommended home flluids on diarrhoea mortality. Int $\mathrm{J}$ Epidemiol. 2010;39(Suppl 1):i75-87

8. Victora CG, Bryce J, Fontaine O. Reducing deaths from diarrhoea through oral rehydration therapy. Bull World Health Organ. 2000;78(10):1246-55.

9. Cheng SX. Calcium-sensing receptor inhibits secretagogue-induced electrolyte secretion by intestine via the enteric nervous system. Am J PhysiolGastrointest Liver Physiol. 2012;303(1):G60-70.

10. Tang L, Cheng CY, Sun X, Pedicone AJ, Mohamadzadeh M, Cheng SX. The Extracellular Calcium-Sensing Receptor in the Intestine: Evidence for Regulation of Colonic Absorption, Secretion, Motility, and Immunity. Front Physiol. 2016;7:245.

11. Owen JL, Cheng SX, Ge Y, Mohamadzadeh M. The role of the calcium-sensing receptor in gastrointestinal inflammation. Semin Cell DevBiol. 2016;49:44-51.

12. Cheng SX, Bai H X, Gonzalez-Peralta R, Mistry PK, Gorelick FS. Calcium ameliorates diarrhea in immune compromised children. J PediatrGastroenterol Nutr.2013; 56(6): 641-4.

13.Agustina R, Kok FJ, van de Rest O, Fahmida U, Firmansyah A, Lukito W, et al. Randomized trial of probiotics and calcium on diarrhea and respiratory tract infections in Indonesian children. Pediatrics. 2012;129(5):e1155-64.

14. Vesikari clinical severity scoring system manual .Lewis $\mathrm{K}$. https://path.azureedge.net/media/documents/VAD_vesikari_scoring _ manual.pdf .Accessed April 28, 20210.

15. Sweetser S. Evaluating the patient with diarrhea: a case-based approach. Mayo Clin Proc. 2012;87(6):596-602.

16. Laboratory guidelines for acute diarrhea. Suggested physician ordering plan for the laboratory examination of stool specimens. Washington State Department of Health Clinical Laboratory Advisory Council. Originally published: October 2010/April2014. 
http://www.doh.wa.gov/Portals/1/Documents/2700/AcuteD.pdf.Acces sed June 21, 2017.

17.https://data.unicef.org/wp-content/uploads/2016/11/Ending-Prevent able-Child-DeathsfromPneumonia-and-Diarrhoea-by-2025.pdf.Acce ssed April 28, 2020.

18. Turner MJ, Angel JB, Woodend K, Giguère P. The efficacy of calcium carbonate in the treatment of protease inhibitor-induced persistent diarrhea in HIV-infected patients. HIV Clin Trials. 2004;5(1):19-24.

19. Dadu R, Hu MI, Cleeland C, Busaidy NL, Habra M, Waguespack SG, et al. Efficacy of the Natural Clay, Calcium Aluminosilicate AntiDiarrheal, in Reducing Medullary Thyroid Cancer-Related Diarrhea and Its Effects on Quality of Life: A Pilot Study. Thyroid. 2015;25(10):1085-90

20. Bovee-Oudenhoven IM, Lettink-Wissink ML, Van Doesburg W, Witteman BJ, Van Der Meer R. Diarrhea caused by entero toxigenic Escherichia coli infection of humans is inhibited by dietary calcium. Gastroenterology. 2003;125(2):469-76.

21. Devrajani BR, Ali Shah SZ, Shaikh S, Shaikh S, Essa S. Hypocalcemia in acute gastroenteritis (A case control study at department of internal medicine). World Appl Sci J. 2009;7(6):77780 . 